\title{
Análise da inserção do estudo sobre tecnologias digitais nas matrizes curriculares dos cursos de licenciatura presenciais do Campus Central da Universidade Federal do Rio Grande do Norte
}

\author{
Amanda Maria D. de Oliveira ${ }^{1}$, Rodolfo A. de Carvalho ${ }^{1}$, Dennys L. Maia ${ }^{1}$ \\ ${ }^{1}$ Instituto Metrópole Digital - Universidade Federal do Rio Grande do Norte (UFRN) \\ Lagoa Nova - 59.064-741 - Natal - RN - Brasil \\ \{amandamariadomingos, rodolfooac\}@gmail.com, dennys@imd.ufrn.br
}

\begin{abstract}
Today we are immersed in access to digital technological resources, making it necessary for these technologies to be integrated into the school life of the student and the teacher. Based on a survey of disciplines offered in undergraduate courses at the Federal University of Rio Grande do Norte, we aim to analyze the curricular matrices of these courses and how the initial teacher training is being used Of Digital Technologies of information and communication (TDIC) in education. From the study of sixteen disciplines offered in 21 undergraduate courses, from four areas of knowledge, we can perceive that only two of the courses analyzed offer disciplines related to TDIC in pedagogical practice. This shows a need to reformulate the curriculum of undergraduate courses analyzed.
\end{abstract}

Resumo. Nos dias de hoje estamos imersos no acesso a recursos tecnológicos digitais, tornando necessário que essas tecnologias sejam integradas, também, a vida escolar do aluno e do professor. A partir de um levantamento de disciplinas ofertadas em cursos presenciais de licenciatura do Campus Central da Universidade Federal do Rio Grande do Norte, temos como objetivo analisar as matrizes curriculares desses cursos e como está sendo a formação inicial de professores para utilização das Tecnologias Digitais de Informação e Comunicação (TDIC) na educação. A partir do estudo de dezesseis disciplinas ofertadas em 21 cursos de licenciatura, de quatro áreas de conhecimento, podemos perceber que apenas dois dos cursos analisados ofertam disciplinas relacionadas às TDIC na prática pedagógica. O que evidencia uma necessidade de reformulação do currículo dos cursos de licenciatura analisados.

\section{Introdução}

Vivemos em uma era que o acesso a recursos tecnológicos digitais é quase intrínseco às atividade cotidianas. Seja no momento da aquisição de um produto ou no ato da matrícula em um curso, informar o e-mail e o telefone para contato, por exemplo, são campos de preenchimento obrigatório nos formulários. Os gestores das instituições de ensino informatizam o processo burocrático para otimizá-lo. Cada vez mais escolas adotam os sistemas informatizados para gestão, por exemplo, de notas e frequências, tendo em vista que isto beneficia gestores, alunos e professores, e em sala de aula isso 
não pode ser diferente. Tecnologia e Educação são parceiras no processo de ensino e aprendizagem, seja dentro ou fora da sala de aula, "a educação e a tecnologia são indissociáveis" [Kenski 2007].

As escolas passam por momentos de mudanças, principalmente, devido a presença das Tecnologias Digitais da Informação e Comunicação (TDIC) no seu espaço, tornando necessário que essas tecnologias sejam integradas a vida escolar do aluno e do professor. Por isso, deve-se discutir não apenas como as TDIC serão utilizadas por alunos mas, também, como os professores vão utilizar, pois "Pensar a educação e a escola implica, necessariamente, pensar o papel do professor[...]" [Preto e Bonilla 2012, p. 57], ou seja, devemos pensar como está ocorrendo a preparação docente para a utilização das TDIC para fins pedagógicos.

As escolas vêm se equipando com laboratórios de informática, rede de acesso à internet e ferramentas digitais para melhor atender aos alunos que já estão inseridos na cultura digital. Porém, é preciso que esses recurso propiciem não só aos alunos, mas, também, aos professores condições de ensino e aprendizagem mais significativas. Ainda é do professor o papel de norteador, mesmo com a presença das TDIC na sala de aula, da aprendizagem do aluno, propondo situações para o aluno em que o uso das tecnologias torna a aprendizagem significativa [Maia e Barreto 2012].

No cenário atual, falar em formação de professores não se trata apenas de propor estudos sobre o conteúdo a ser ensinado, trata-se, também, "de outro universo formativo para o professor que emergiu depois da potencial 'popularização' da internet, das possibilidades de conectividade e da busca pela qualidade nas formações diante das novas tecnologias" [Lima e Loureiro 2015], de forma a prepará-los para a realidade da sala de aula que o aguarda.

O Conselho Nacional de Educação/Conselho Pleno (CNE/CP), que institui as Diretrizes Curriculares Nacionais (DCN) para a formação de professores da Educação Básica, com a Resolução no 1/2002, em seu Artigo $2^{\circ}$, Inciso IV, prevê "o uso de tecnologias da informação e comunicação e de metodologias, estratégias e materiais de apoio inovadores" como uma das "formas de orientação inerentes à formação para a atividade docente" [BRASIL 2002, p.1].

Utilizando a Universidade Federal do Rio Grande do Norte (UFRN) como estudo de caso, este artigo apresenta uma análise de como está ocorrendo a formação dos novos docentes, a partir da estrutura curricular, nos dezessete cursos de licenciatura presenciais do Campus Central da UFRN.

\section{Preparação dos professores para o uso pedagógico das TDIC}

As TDIC são ferramentas versáteis e desafiadoras que atualmente estão presentes dentro das casas, trabalho, escola e, até mesmo, configuram-se como atividades de lazer. Face aos padrões estabelecidos das tecnologias analógicas, as TDIC trouxeram benefícios, como facilidade de comunicação e acesso a um maior número de informações sobre assuntos diversos, mas também trouxeram problemas para quem nasceu em uma época distante da atual, como a necessidade de apropriação e inserção dos indivíduos neste contexto [Costa 1999]. 
É importante pensar como as TDIC vêm potencializar o trabalho de diversos profissionais, inclusive do professor, pois não se trata apenas da inserção de mais um recurso na sala aula, mas de uma transformação, que vai além dos espaços físicos em que ocorre a educação [Kenski 2007].

[...]no atual contexto tecnológico, consideramos imperativo o tratamento dessas questões no primeiro curso e de maior duração que o professor terá em sua vida acadêmica e profissional. Ademais, as Universidades, instituições prioritariamente responsáveis pela formação desses profissionais, não pode ficar aquém das demandas por TDIC na sociedade e na Educação. [Monteiro et al 2015, p. 455]

Deste modo, a formação e a preparação para o uso adequado das TDIC como recursos pedagógicos precisa ser feita desde a formação inicial do docente. Tais recursos devem fazer parte do aprendizado diário dos futuros professores ainda enquanto alunos dos cursos de licenciaturas.

As TDIC oportunizam diferentes formatos de utilização, contando com modi operandi e conhecimento desenvolvido por seu utilizador, neste caso, o professor. Para que isso ocorra, os professores precisam conhecer as possibilidades que têm disponíveis, a integração das TDIC na prática docente deve estar ligada com sua formação inicial e o conhecimento adquirido para sua atuação. Sendo necessário, sobretudo, que os professores sintam que é cômodo utilizar esses recursos como auxiliadores didáticos. Ou seja, que tenham o mínimo conhecimento de procedimentos técnicos básicos para sua utilização, que possam analisá-los criticamente e criar suas próprias possibilidades pedagógicas, partindo da integração desses meios com suas atividades de ensino [Kenski 2003].

Percebendo tal necessidade, observamos o quão é indispensável que os novos professores estejam preparados e formados para esses novos ambientes escolares:

[...]nossos alunos mudaram radicalmente e são hoje falantes nativos da linguagem digital dos computadores, videogames e Internet; já os imigrantes digitais têm 'sotaque' quando usam essa linguagem (como, por exemplo, ao ler o manual de um game), o que estaria alimentando uma grande descontinuidade entre essas gerações. Nossos professores, imigrantes digitais, falam uma linguagem desatualizada (aquela da era pré-digital) e estão lutando para ensinar uma população que fala uma linguagem inteiramente nova. $\mathrm{O}$ currículo tradicional inclui a leitura, escrita, aritmética e raciocínio lógico, dentre outros conteúdos, enquanto o currículo do futuro deveria incluir também software, hardware, robótica, nanotecnologia e genoma, assim como ética, política, sociologia, linguagens e outras questões que os acompanham -- mas quantos imigrantes digitais estão preparados para ensiná-lo? [Mattar 2010, p.10]

Assim, durante o curso com a maior duração no processo formativo do docente, deve ser iniciada a experiência de uso pedagógico dos recursos digitais pois, se não for vivenciada pelos futuros professores, as dificuldades posteriores tenderão a ser maiores [Maia e Barreto 2014]. Expostos os argumentos para o estudo, apresentamos o percurso metodológico do estudo e passamos para as discussões e análises dos dados. 
VI Congresso Brasileiro de Informática na Educação (CBIE 2017)

Anais do XXIII Workshop de Informática na Escola (WIE 2017)

\section{Metodologia}

Esta pesquisa foi realizada em 21 cursos de licenciatura presenciais do campus Central da UFRN, e se caracterizou como uma pesquisa exploratória. Gil (1999) ressalta que a pesquisa exploratória é desenvolvida no sentido de proporcionar uma visão geral acerca de determinado fato. Portanto, esse tipo de pesquisa é realizado, sobretudo, quando o tema escolhido é pouco explorado e torna-se difícil formular hipóteses precisas e operacionalizáveis. Baseado nisso, foi feito um levantamento e estudo sobre as disciplinas ofertadas para os estudantes de licenciatura presencial da UFRN.

Os cursos escolhidos para análise são das áreas comuns à educação básica. Para fontes documentais, recorreu-se ao Sistema Integrado de Gestão de Atividades Acadêmicas (SIGAA) da UFRN. Este sistema permitiu o acesso às informações utilizadas nesta pesquisa, quais sejam: currículo ainda ativos, em que se identificou, a partir de palavras-chave, as disciplinas relacionadas às TDIC; obrigatoriedade da disciplina; e ementa.

Este estudo foi iniciado com o levantamento dos cursos de licenciatura presenciais ofertados no campus central da UFRN, através da página de cursos de graduação do SIGAA. Em seguida foi realizada a busca e verificação do currículo ativo mais recente, informado no sistema, na sessão de currículos disponível para cada um dos cursos de licenciatura, o que possibilitou a contagem individual das disciplinas obrigatórias e optativas ofertadas. De posse da estrutura curricular de todos os cursos de licenciatura foi realizada uma busca por meio de palavras-chave - tecnologia(s), informática, computação, computador(es), recurso(s), mídia(s) - no título das disciplinas, visto que essa é a primeira informação consultada e disponível para o aluno no ato da matrícula. $\mathrm{O}$ objetivo dessa busca foi identificar as disciplinas que tratavam das TDIC, de forma geral. Após a identificação das disciplinas na busca realizada, foi feito uma análise de sua ementa para verificar se a disciplina realmente tratava da aplicação das TDIC em sala de aula.

É importante ressaltar que um mesmo curso de licenciatura ofertado em turnos distintos são tratados como cursos distintos, isso se deve, provavelmente, em razão da diferença de carga horária e distribuição das disciplinas.

\section{Análise dos dados}

Ao consultarmos as estruturas curriculares de 21 cursos presenciais de licenciatura por meio do SIGAA, encontramos um total de 16 disciplinas que continham pelo menos uma das palavras-chave buscadas. Em onze cursos não encontramos nenhuma disciplina, sendo que em nenhum dos cursos haviam mais que duas disciplinas, como apresenta o Quadro 1. Na coluna cursos as informações de cada curso estão sistematizadas da seguinte forma: Nome do curso - Campus - Perfil de formação Modalidade de ensino - Turno. Desta forma, o curso presencial de Licenciatura em Ciências Biológicas do Campus central do turno Manhã/Tarde seria apresentado como “CIÊNCIAS BIOLÓGICAS - Campus Central - LICENCIATURA - Presencial - MT".

\section{Quadro 1 - Levantamento de disciplinas}


VI Congresso Brasileiro de Informática na Educação (CBIE 2017)

Anais do XXIII Workshop de Informática na Escola (WIE 2017)

\begin{tabular}{|c|c|c|c|}
\hline \multirow{2}{*}{ Curso } & \multicolumn{3}{|c|}{$\begin{array}{l}\text { Informática/Tecnologias } \\
\text { Educacionais }\end{array}$} \\
\hline & Obrigatórias & Optativas & $\begin{array}{c}\text { Tota } \\
1\end{array}$ \\
\hline $\begin{array}{l}\text { CIÊNCIAS BIOLÓGICAS - Campus central- LICENCIATURA - } \\
\text { Presencial - MT }\end{array}$ & 0 & 0 & 0 \\
\hline $\begin{array}{l}\text { CIÊNCIAS BIOLÓGICAS - Campus central - LICENCIATURA - } \\
\text { Presencial - N }\end{array}$ & 0 & 0 & 0 \\
\hline FÍSICA - Campus central - LICENCIATURA - Presencial - N & 0 & 2 & 2 \\
\hline MATEMÁTICA - Campus central - LICENCIATURA - Presencial - MT & 1 & 1 & 2 \\
\hline MATEMÁTICA - Campus central - LICENCIATURA - Presencial - N & 1 & 1 & 2 \\
\hline QUÍMICA - Campus central - LICENCIATURA - Presencial - M & 0 & 0 & 0 \\
\hline QUÍMICA - Campus central - LICENCIATURA - Presencial - N & 0 & 0 & 0 \\
\hline CIÊNCIAS SOCIAIS - Campus central - LICENCIATURA - Presencial - N & 0 & 1 & 1 \\
\hline FILOSOFIA - Campus central - LICENCIATURA - Presencial - N & 0 & 0 & 0 \\
\hline GEOGRAFIA - Campus central - LICENCIATURA - Presencial - N & 0 & 0 & 0 \\
\hline HISTÓRIA - Campus central - LICENCIATURA - Presencial - N & 1 & 0 & 1 \\
\hline HISTÓRIA - Campus central - LICENCIATURA - Presencial - M & 1 & 0 & 1 \\
\hline $\begin{array}{l}\text { LETRAS - LINGUA PORTUGUESA - Campus central - LICENCIATURA } \\
\text { - Presencial - N }\end{array}$ & 0 & 0 & 0 \\
\hline $\begin{array}{l}\text { LETRAS - LINGUA PORTUGUESA - Campus central - LICENCIATURA } \\
\text { - Presencial - M }\end{array}$ & 0 & 0 & 0 \\
\hline $\begin{array}{l}\text { EDUCAÇÃO FÍSICA - Campus central - LICENCIATURA - Presencial - } \\
\text { MT }\end{array}$ & 0 & 2 & 2 \\
\hline PEDAGOGIA - Campus central - LICENCIATURA - Presencial - N & 1 & 1 & 2 \\
\hline PEDAGOGIA - Campus central - LICENCIATURA - Presencial - T & 1 & 1 & 2 \\
\hline $\begin{array}{l}\text { LETRAS - FRANCÊS - Campus central - LICENCIATURA - Presencial - } \\
\text { M }\end{array}$ & 0 & 0 & 0 \\
\hline LETRAS - INGLÊS - Campus central - LICENCIATURA - Presencial - M & 0 & 0 & 0 \\
\hline $\begin{array}{l}\text { LETRAS - LÍNGUA ESPANHOLA - Campus central - LICENCIATURA - } \\
\text { Presencial - N }\end{array}$ & 0 & 0 & 0 \\
\hline $\begin{array}{l}\text { LETRAS - LÍNGUA PORTUGUESA E LIBRAS - Campus central - } \\
\text { LICENCIATURA - Presencial - N }\end{array}$ & 0 & 1 & 1 \\
\hline $\begin{array}{l}\text { CIÊNCIAS BIOLÓGICAS - Campus central - LICENCIATURA - } \\
\text { Presencial - MT }\end{array}$ & 0 & 0 & 0 \\
\hline
\end{tabular}


VI Congresso Brasileiro de Informática na Educação (CBIE 2017)

Anais do XXIII Workshop de Informática na Escola (WIE 2017)

Dentre os cursos de licenciatura analisados podemos ver que (Gráfico 1), ainda os cursos que ofertam disciplinas relacionadas às TDIC, de forma geral, são minoria.

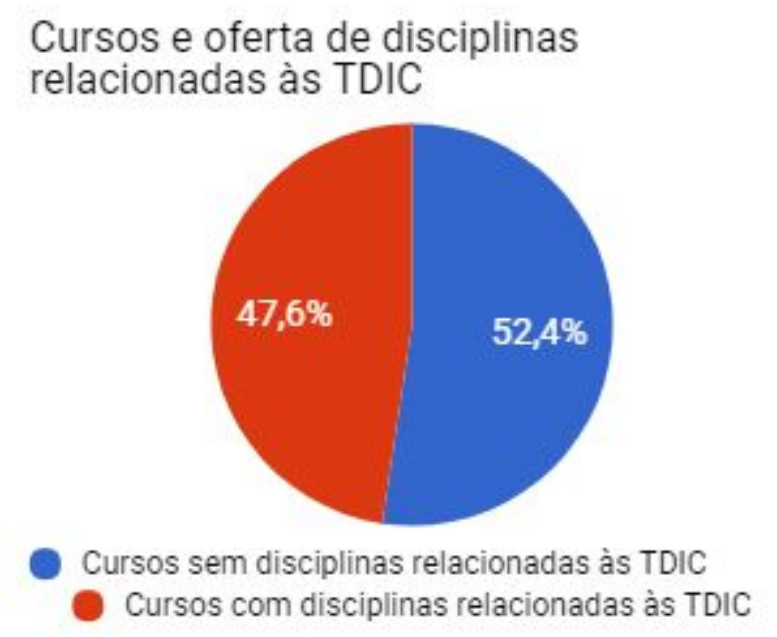

Gráfico 1 - Cursos e oferta de disciplinas relacionadas às TDIC

Dentre as disciplinas encontradas notamos que nenhum curso excede o total de duas disciplinas, como mostra o Gráfico 2. Havendo ainda cursos nos quais só foram encontradas disciplinas optativas, ou seja, que o aluno não é obrigado a cursar durante a graduação. Sabendo que o percentual da carga horária optativa é muito menor que o do currículo obrigatório, porém o número de disciplinas a escolher é muito amplo, muitos alunos acabam, assim como foi feito nesta pesquisa, por só analisar, de fato, apenas aquelas disciplinas cujo título lhe desperte interesse imediato.

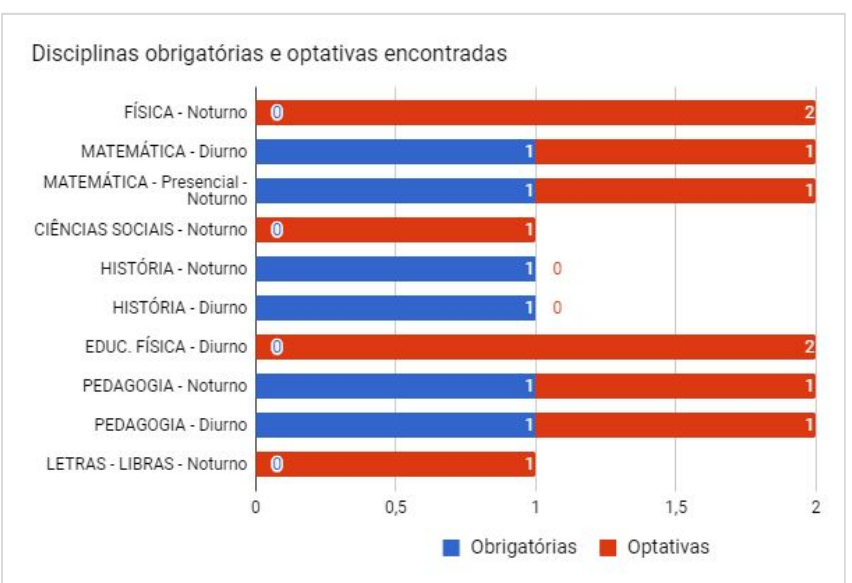

\section{Gráfico 2 - Disciplinas obrigatórias e optativas encontradas}

É importante observar que nos cursos de Licenciatura em História foi encontrada a disciplina optativa "História da Técnica e da Tecnologia", que não se trata de uma disciplina voltada para o uso das TDIC na prática docente. Mas foi identificada na busca pela palavra-chave "tecnologia". O mesmo ocorre no curso de Licenciatura em Física, no qual as duas disciplinas encontradas na busca tratam de disciplinas optativas voltadas à programação e uso instrumental do computador, sendo elas: "Introdução a 
VI Congresso Brasileiro de Informática na Educação (CBIE 2017)

Anais do XXIII Workshop de Informática na Escola (WIE 2017)

Informática" e "Linguagens de Programação". Podemos observar as ementas dessas disciplinas no Quadro 2.

Quadro 2 - Ementas disciplinas não relacionadas às TDIC na prática docente

\begin{tabular}{|l|l|l|}
\hline \multicolumn{1}{|c|}{ Curso } & \multicolumn{1}{|c|}{ Disciplina } & \multicolumn{1}{c|}{ Ementa } \\
\hline $\begin{array}{l}\text { Licenciatura em } \\
\text { História }\end{array}$ & $\begin{array}{l}\text { His0060 - } \\
\text { História da } \\
\text { Técnica e da }\end{array}$ & $\begin{array}{l}\text { Tefinições: técnica e tecnologia. Por uma nova história } \\
\text { das tecnologias. Técnica e hominização. Culturas, } \\
\text { diversidades e técnicas. Tecnologia e civilização. } \\
\text { Tecnologia, produção e riqueza. Poder e tecnologia. } \\
\text { Consumo, técnica e status. Conhecimento e tecnologia. } \\
\text { Espaço, mobilidade e tecnologia. }\end{array}$ \\
\hline Licenciatura em Física & $\begin{array}{l}\text { Introdução à } \\
\text { Informática }\end{array}$ & $\begin{array}{l}\text { O computador, sistemas operacionais, outros softwares } \\
\text { básicos, software de suporte e aplicativos com a área } \\
\text { de abordagem; Micro-Informática; Noções de redes; } \\
\text { que estejam sendo mais utilizados no mercado e } \\
\text { disponíveis na UFRN. }\end{array}$ \\
\hline \multirow{2}{*}{ Licenciatura em Física } & $\begin{array}{l}\text { Linguagens de } \\
\text { Programação }\end{array}$ & $\begin{array}{l}\text { Estudo pormenorizado de linguagens de alto nível: } \\
\text { Estruturas de dados de controle, recursos de } \\
\text { entrada/saída, gerenciamento de memória, integração } \\
\text { com o hardware, características específicas. } \\
\text { Desenvolvimento de aplicações. }\end{array}$ \\
\hline
\end{tabular}

É notório que nos cursos de licenciatura das Ciências Exatas, sendo eles Matemática, Química e Física, o conceito de tecnologia está amplamente voltado ao aprendizado de programação e uso do computador como ferramenta para o discente. Desta forma, não é pensando na sua docência ou como um aluno que pode ser utilizador de TDIC em suas práticas docentes. Ou seja, é pensando na informática como uso instrumental e não pedagógico, embora os cursos de licenciatura, diferente dos bacharelados, tenham o objetivo de formar professores para a Educação Básica.

Dentre os dez cursos identificados durante a busca, apenas os cursos de Licenciatura em Matemática e Pedagogia ofertam disciplinas obrigatórias que tratam, de fato, da aplicação das TDIC na prática docente, como podemos ver em suas ementas no Quadro 3.

\section{Quadro 3 - Ementas disciplinas obrigatórias}

\begin{tabular}{|l|l|l|}
\hline \multicolumn{1}{|c|}{ Curso } & \multicolumn{1}{|c|}{ Disciplina } \\
$\begin{array}{l}\text { Licenciatura em } \\
\text { Matemática }\end{array}$ & $\begin{array}{l}\text { MAT1512 - } \\
\text { Informática no } \\
\text { Ensino da } \\
\text { Matemática }\end{array}$ & $\begin{array}{l}\text { Estudo e análise de experiências educacionais com a } \\
\text { utilização de softwares e sítios especializados da internet no } \\
\text { ensino-aprendizagem de Matemática. }\end{array}$ \\
\hline $\begin{array}{l}\text { Licenciatura em } \\
\text { Pedagogia }\end{array}$ & $\begin{array}{l}\text { PEC5042 - } \\
\text { Tecnologia e } \\
\text { Educação }\end{array}$ & $\begin{array}{l}\text { O curso tem como objetivos apresentar o conceito de } \\
\text { Tecnologia Educacional e discutir questões sobre o processo } \\
\text { ensino-aprendizagem (presencial ou distância) mediado pelas } \\
\text { Tecnologias da Informação e Comunicação (TIC) e as } \\
\text { implicações deste uso. As teorias da comunicação: as relações } \\
\text { dos meios de comunicação e informação com a educação. Os }\end{array}$ \\
\hline
\end{tabular}


VI Congresso Brasileiro de Informática na Educação (CBIE 2017)

Anais do XXIII Workshop de Informática na Escola (WIE 2017)

\begin{tabular}{|l|l|}
\hline & $\begin{array}{l}\text { Meios: seu suporte físico e sua linguagem. Os usos dos Meios } \\
\text { no ensino e na produção de materiais didáticos. }\end{array}$ \\
\hline
\end{tabular}

A partir do fato de que apenas dois cursos ofertam disciplinas obrigatórias relacionadas à prática docente e o uso das TDIC, podemos notar a necessidade de uma reflexão e uma, possível, reformulação das estruturas curriculares. Isso é oportuno para os cursos de licenciatura que não ofertam tais disciplinas e os que pouco ofertam. A inexistência dessas disciplinas no currículo é um dos aspectos que não contribuem para que os futuros docentes incorporem as TDIC em suas futuras práticas pedagógicas, vivenciando ativamente o uso das ferramentas tecnológicas em sua formação inicial [Monteiro et al 2015].

Dentre os sete cursos que ofertam disciplinas optativas encontradas na busca, apenas nos cursos de Licenciatura em Ciências Sociais, Educação Física e Letras Língua Portuguesa e Libras são ofertadas disciplinas que tratam do uso das TDIC em sala de aula, como vemos no Quadro 4.

Quadro 4 - Ementas disciplinas optativas

\begin{tabular}{|c|c|c|}
\hline Curso & Disciplina & Ementa \\
\hline $\begin{array}{l}\text { Licenciatura em } \\
\text { Ciências Sociais }\end{array}$ & $\begin{array}{l}\text { PEC0501 - } \\
\text { Tecnologias } \\
\text { Educacionais e } \\
\text { Elaboração de } \\
\text { Materiais Didáticos }\end{array}$ & $\begin{array}{l}\text { As teorias da comunicação: as relações dos meios de } \\
\text { comunicação e informação com a educação. Os } \\
\text { Meios: seu suporte físico e sua linguagem. Os usos } \\
\text { dos Meios no ensino e na produção de materiais } \\
\text { didáticos. }\end{array}$ \\
\hline $\begin{array}{l}\text { Licenciatura em } \\
\text { Educação Física }\end{array}$ & $\begin{array}{l}\text { DEF0073 - Mídia, } \\
\text { tecnologia e educação } \\
\text { física }\end{array}$ & $\begin{array}{l}\text { As práticas corporais e sua interação com a mídia. O } \\
\text { cinema, a televisão, o computador e o rádio como } \\
\text { mídias que veiculam discursos sobre as práticas } \\
\text { corporais e sobre o imaginário do profissional de } \\
\text { Educação Física. Análise crítico-social da mídia como } \\
\text { recurso didático para a intervenção pedagógica na } \\
\text { Educação Física. A necessidade de educar no meio e } \\
\text { para o meio. Aspectos teórico-metodológicos da } \\
\text { Educação Física para o trato com as mídias. }\end{array}$ \\
\hline $\begin{array}{l}\text { Licenciatura em } \\
\text { Educação Física }\end{array}$ & $\begin{array}{l}\text { DEF0060 - } \\
\text { Informática em } \\
\text { educação física e } \\
\text { esportes }\end{array}$ & $\begin{array}{l}\text { Noções básicas de informática, importâncias e } \\
\text { vantagens. utilização do Word, PowerPoint e da } \\
\text { planilha do excel. aplicação do CorelDRAW e do } \\
\text { pagemaker relacionados à atividade física. uso da } \\
\text { internet e do correio eletrônico como integrantes do } \\
\text { processo de atuação e de desenvolvimento } \\
\text { profissional. utilização dos principais periféricos e da } \\
\text { multimídia na vida profissional. Apresentações de } \\
\text { trabalhos acadêmicos com recursos da informática. }\end{array}$ \\
\hline $\begin{array}{l}\text { Letras Língua } \\
\text { Portuguesa e Libras }\end{array}$ & $\begin{array}{l}\text { LET0548 - Educação } \\
\text { de surdos e novas } \\
\text { tecnologias }\end{array}$ & $\begin{array}{l}\text { Oferecer aos educandos surdos o conhecimento de } \\
\text { tecnologia de apoio. A utilização do vídeo, da } \\
\text { videoconferência, da Internet, das redes e multimídia } \\
\text { na educação de surdos. Conhecer alguns softwares } \\
\text { disponíveis específicos para surdos. }\end{array}$ \\
\hline
\end{tabular}


É visto que a maioria das disciplinas ainda são optativas, ou seja, o aluno tem a opção de escolher se irá cursá-las ou não, o que influencia diretamente na sua formação inicial. Porém é imprescindível que o currículo da graduação seja condizente com a atual realidade do educador, de forma que ele possa apropriar-se da cultura digital e das TDIC e venha a "utilizá-las na própria aprendizagem e na prática pedagógica e refletir sobre por que e para que usar a tecnologia, como se dá esse uso e que contribuições ela pode trazer à aprendizagem e ao desenvolvimento do currículo" [ALMEIDA, 2010, p.68].

\section{Considerações finais}

Após a análise quantitativa das disciplinas ofertadas relacionadas à utilização de TDIC, sua obrigatoriedade ou não, podemos identificar que existe uma escassez dessas disciplinas no currículo. Ainda foi possível observar através da ementa que a maioria das disciplinas tratam das TDIC apenas como recurso tecnológico, não havendo uma reflexão sobre sua aplicação pedagógica.

Sabendo que durante sua vida profissional o docente poderá deparar-se com um novo perfil de aluno e uma escola imersa na cultura digital, envolvendo o uso de recursos tecnológico na sala de aula, julgamos que a formação inicial de professores deve oferecer não apenas condições de criticidade do conteúdo mas, também, em relação às TDIC e a prática pedagógica. Para os cursos analisados, isso exige uma reformulação na estrutura curricular, para que o âmbito da tecnologias possa ser contemplado. Por isso, acreditamos que os currículos das licenciaturas deveriam ser pensados, por exemplo, em conjunto com áreas correlatas às TDIC na educação, como é o caso do curso de Bacharelado em Tecnologia da Informação, com ênfase em Informática Educacional, ofertado na mesma universidade.

Pensando em trabalhos futuros, objetivamos fazer uma pesquisa exploratória acerca dos ambientes em que são ofertadas as disciplinas diretamente relacionadas às práticas pedagógicas com o uso das TDIC. Pois no contexto que o discente desenvolve o pensamento crítico é necessário que ele vivencie também a prática. É importante que o desenvolvimento dessa metodologia vá além das disciplinas que foram de interesse neste trabalho, apesar de não termos como constatar que não é tratado do uso das TDIC em sala de aula em outras disciplinas, motivando que a pesquisa seja feita de forma investigativa dentro das demais disciplinas obrigatórias.

\section{Referências}

Almeida, M. E. B. (2010). "Transformações no trabalho e na formação docente na educação a distância on-line”. In Aberto, v. 23, n. 84, p. 67-77.

BRASIL. Resolução CNE/CP No 1, de 18 de Fevereiro de 2002. "Institui Diretrizes Curriculares Nacionais para a Formação de Professores da Educação Básica, em nível superior, curso de licenciatura, de graduação plena". Disponível em: $<$ http://portal.mec.gov.br/seesp/arquivos/pdf/res1_2.pdf>. Acesso em: 10 mai. 2017.

Costa, J. A. (1999). "O papel da escola na sociedade atual: implicações no ensino das ciências". Millenium editora. 
VI Congresso Brasileiro de Informática na Educação (CBIE 2017)

Anais do XXIII Workshop de Informática na Escola (WIE 2017)

Gil, A. C. (1999). "Métodos e técnicas de pesquisa social”. (5a ed.). São Paulo: Atlas.

Kenski, V. M. (2007). "Educação e tecnologias”. Papirus editora.

Kenski, V. M. (2003). “Tecnologias e ensino presencial e a distância”. Campinas, SP: Papirus.

Lima, L. \& Loureiro, R. (2015). “A integração entre Docência e Tecnologias Digitais da Informação e Comunicação na Formação de Licenciandos”. In Anais do Workshop de Informática na Escola, v. 21, n. 1, p. 395.

Maia, D. L., \& Barreto, M. C. (2014). "Ensinar Matemática com Uso de Tecnologias Digitais: qual a Representação Social de pedagogos em formação?”.

Maia, D. L. \& Barreto, M. C. (2012). “Tecnologias digitais na educação: uma análise das políticas públicas brasileiras”. In Educação, Formação \& Tecnologias - ISSN 1646-933X, v. 5, n. 1.

Mattar, J. (2010). "Games em educação: como os nativos digitais aprendem”. São Paulo/SP: Pearson Prentice Hall.

Monteiro, J. et al. (2015). "Formação Inicial Docente para as TDIC: Análise a Partir do Curso de Pedagogia do Campus Central da UFRN". In Anais do Workshop de Informática na Escola, v. 21, n. 1, p. 454.

Pretto, N. L. \& Bonilla, M. H. S. (2012). "O que o software livre tem a ver com a educação?”. In Formação de professores para as tecnologias digitais: software livre e educação a distância. $1^{\mathrm{a} e d}$. Brasília/DF: Liber Livro, v. 1.

SIGAA. UFRN. Disponível em: <www.sigaa.ufrn.br>. Acesso em: 17 abr. 2017. 